\title{
CA 19-9 levels in patients with acute pancreatitis due to gallstone and metabolic/toxic reasons
}

\author{
DOmer Burcak Binicier ${ }^{1}$ \\ (iD) Zehra Betul Pakoz ${ }^{1}$
}

1. Tepecik Education and Research Hospital, Department of Gastroenterology. Yenisehir-Izmir/Turkey.

http://dx.doi.org/10.1590/1806-9282.65.7.965

\section{SUMMARY}

OBJECTIVE: Acute pancreatitis (AP) is an important clinical event with an increased frequency due to increased life expectancy, obesity, and alcohol use. There are some data about the elevation of carbohydrate antigen (CA) 19-9 levels in benign and malignant pancreaticobiliary events in the literature, but in AP they are limited. The aim of this study was to evaluate the CA 19-9 level in patients with $A P$ and determine its relationship according to the cause.

METHODS: Between 2010-2018, 173 patients evaluated with CA 19-9 levels as well as by standard laboratory tests were included in the study. CA 19-9 levels and laboratory findings were compared in patients with pancreatitis due to gallstone (group 1) and metabolic/ toxic reasons such as hyperlipidemia, alcohol, or drug use (group 2).

RESULTS: There were 114 (66\%) patients in the group 1 and 59 (34\%) patients in the group 2. The majority of patients with high CA 19-9 level were in group 1 (92.1\% vs 6.8\%). CA 19-9 level, as well as amylase, lipase, AST, ALT and bilirubin levels were found to be statistically higher in patients with AP due to gallstone compared to patients with metabolic/toxic AP.

CONCLUSIONS: Patients with AP due to gallstone, were found to have a high level of CA 19-9 at admission. Early stage CA 19-9 levels may contribute to standard laboratory tests in the etiology of the disease in patients diagnosed with AP.

KEYWORDS: Pancreatitis. Gallstones. CA-19-9 Antigen.

\section{INTRODUCTION}

Acute pancreatitis (AP) is an important gastrointestinal event commonly encountered all over the world. Although there are regional differences, the first two etiologies that cause AP are gallstone and alcohol (60$80 \%)^{1}$. Determining the underlying etiology is important to determine the treatment roadmap and the need for endoscopic retrograde cholangiopancreatography (ERCP). In AP with metabolic and toxic causes, such as alcohol or hyperlipidemia, normal or moderate transaminases and cholestatic enzymes may be elevated, whereas gallstone-associated AP may be associated with increased levels of transaminases and cholestatic enzymes. Even in cases where transaminase and cholestatic enzyme elevations are associated, false positive results may be encountered. In addition, a laboratory parameter alone cannot differentiate between gallstone and other causes. For this reason, additional imaging methods such as magnetic resonance cholangiopancreatography (MRCP), endoscopic ultrasound (EUS), and ERCP are frequently used.

Carbohydrate antigen (CA) 19-9 is a SiaLe-Lewis blood group antigen which was first described in murine monoclonal antibodies against colorectal carcinoma epithelial cells ${ }^{2}$. In many studies, CA 19-9 
levels have been shown to increase in tumors involving the pancreas and biliary tract ${ }^{3-7}$. In addition, in the patients with malignant tumors such as stomach, ovary, hepatocellular and colorectal carcinomas and in benign cases (pancreatitis, cholangitis, and choledocholithiasis) involving the biliary tree have been shown to increase levels ${ }^{8-11}$. There have also been case reports that found elevated CA 19-9 levels may be seen in cases of tuberculosis, infections, various rheumatological, and benign renal events ${ }^{12-15}$.

In this study, we aimed to retrospectively investigate the relationship between CA 19-9 levels and pancreatitis reasons in patients with AP due to gallstone, hyperlipidemia or toxic cause (alcohol and drug), which constitute the first three main etiologies.

\section{METHODS}

\section{Patient selection and data collection}

Patients who were admitted to the emergency department of our hospital with complaints of abdominal pain between May 2010 and May 2018 and diagnosed with AP were included in the study. After analyzing the exclusion criteria of for the 829 diagnosed patients (Table 1), we found that the CA 19-9 levels were examined in 173 at admission in addition to standard blood tests (Figure 1).

The patients were divided into two groups according to their etiology. The patients with AP due to gallstone were placed in the first group, and patients diagnosed with metabolic/toxic AP such as hyperlipidemia, alcohol, or drug were placed on the second group.

AP etiologies were determined according to history, laboratory findings, imaging methods (ultrasonography, computerized tomography (CT), magnetic

\section{TABLE 1. EXCLUSION CRITERIA OF THE STUDY}

\begin{tabular}{|l|} 
Exclusion criteria: \\
\hline $\begin{array}{l}\text { Patients with no identified etiology of pancreatitis (idiopathic } \\
\text { cases) }\end{array}$ \\
\hline $\begin{array}{l}\text { Other patients with rare AP reasons except gallstones, alcohol, } \\
\text { hyperlipidemia and drugs }\end{array}$ \\
\hline $\begin{array}{l}\text { Patients with known malignancy or diagnosed with malignancy } \\
\text { after admission (papilla, pancreas, bile duct neoplasia, etc.) }\end{array}$ \\
\hline Patients with chronic renal failure or active renal disease \\
\hline Patients with a history of chronic rheumatic disease \\
\hline Patients with active lung infection at admission \\
\hline Patients with inflammatory bowel disease \\
\hline Patients without CA 19-9 levels within 24 hours after AP diagnosis \\
\hline
\end{tabular}

resonance imaging (MRI), MRCP, EUS, and ERCP) and, if necessary, pathology results.

\section{Statistical analysis}

Continuous variables were expressed as a mean \pm standard deviation and categorical variables as a percentage. The chi-square test was used to compare categorical values, and the Mann-Whitney U test was used to compare continuous variables between the groups. The Receiver Operating Characteristics (ROC) curve was used to determine the level of CA19-9 to differentiate gallstone and metabolic/toxic causes with optimum sensitivity and specificity. The area under the curve (AUC), positive (PPV) and negative predictive (NPV) values were obtained. The statistical analysis of the study was done using SPSS 25.0 (IBM Statistical Package for Social Sciences software version 25). P $<0.05$ was considered statistically significant.

\section{RESULTS}

Baseline characteristics of the study population

A total of 173 patients (92 female, 81 male) were included in the study. There were 114 (66\%; 71 female, 43 male) patients in the first group (gallstone) and 59 (34\%; 21 female, 38 male) patients in the second group (metabolic/toxic) (Table 2). There was a statistically significant difference between the groups regarding gender distribution $(p=0.001)$. The mean age of the patients was also a statistically significant difference between the groups (65 vs. 52; $p<0.05$ ) (Table3). The demographic data of the patients and baseline characteristic findings at the time of the presentation are summarized in Table 2, 3.

FIGURE 1. PATIENT SELECTION FLOWCHART.

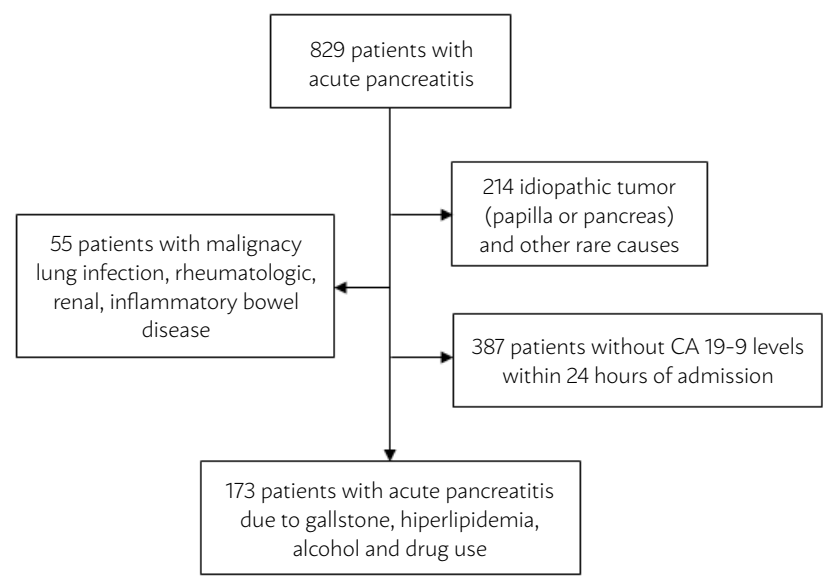


TABLE 2. DISTRIBUTION OF PATIENTS INCLUDED IN THE STUDY

\begin{tabular}{l|l|l} 
Patient groups & $\mathrm{n}$ & \multicolumn{2}{c}{$\%$} \\
\hline Gallstone & 114 & 66 \\
\hline Metabolic and toxic reasons & 59 & 34 \\
- Hyperlipidemia & 21 & 12 \\
- Toxic reasons & 38 & 22 \\
(Alcohol + drugs) & & \\
\hline
\end{tabular}

TABLE 3. DEMOGRAPHIC DATA AND LABORATORY FINDINGS OF THE PATIENTS AT THE TIME OF ADMISSION

\begin{tabular}{|c|c|c|c|}
\hline & Gallstone (n:114) & $\begin{array}{l}\text { Metabolic/toxic } \\
\text { reasons (n:59) }\end{array}$ & p \\
\hline \multicolumn{4}{|l|}{ Gender } \\
\hline Male, $\mathrm{n}$ & 43 & 38 & \multirow{2}{*}{0.001} \\
\hline Female, $\mathrm{n}$ & 71 & 21 & \\
\hline Age, years (range) & $65(22-91)$ & $52(21-87)$ & $<0.05$ \\
\hline Mean CA 19-9 (U/mL), (range) & $206.1(21.6-2,000)$ & $14.6(0.6-108)$ & $<0.05$ \\
\hline Positive CA 19-9, (> $37 \mathrm{U} / \mathrm{mL})$ & $105(92.1 \%)$ & $4(6.8 \%)$ & $<0.05$ \\
\hline Amilase (U/L), (range) & $1,367(78-10,541)$ & $948(67-4,567)$ & $<0.05$ \\
\hline Lipase (U/L), (range) & $3,790(205-25,380)$ & $2,322(174-12,384)$ & $<0.05$ \\
\hline${ }^{*} \mathrm{AST}(\mathrm{U} / \mathrm{L}),($ range $)$ & $297(17-1,399)$ & $105(10-1,137)$ & $<0.05$ \\
\hline${ }^{\star *} \mathrm{ALT}(\mathrm{U} / \mathrm{L})$, (range) & $245(6-1236)$ & $71(8-388)$ & $<0.05$ \\
\hline Total bilirubin (mg/dL), (range) & $3.5(0.3-12.89)$ & $1.2(0.6-11.19)$ & $<0.05$ \\
\hline Direct bilirubin (mg/dL), (range) & $2.07(0.3-794)$ & $1.01(0.3-3.67)$ & $<0.05$ \\
\hline White blood cell (/mm3), (range) & $13,541(5,400-17,000)$ & $12,182(5,390-25,000)$ & 0.615 \\
\hline Hematocrit (\%), (range) & $39.5(25-50)$ & $42(32-47)$ & 0.02 \\
\hline Glucose (mg/dL), (range) & $143(55-341)$ & $173(48-504)$ & 0.111 \\
\hline
\end{tabular}

\section{CA 19-9 level between the groups and cut off} value for prediction

CA 19-9 was detected in 105 (92.1\%) of the patients in the first group, and in $4(6.8 \%)$ of the patients in the second group, more than $37 \mathrm{U} / \mathrm{ml}$ (Normal range of $\mathrm{CA}$ 19-9: 0-37 U/ml) $(\mathrm{p}<0.001)$. There was also a statistically significant difference between the groups regarding mean CA 19-9 values (206.1 vs. 14.6; $p<0.005$ ). The box-plot representation between the groups is shown in Figure 2.

When the cut-off value for CA 19-9 was $37 \mathrm{U} / \mathrm{ml}$, the sensitivity and specificity of the values in the prediction of pancreatitis due to gallstone were measured as 92.1\% and 93.2\%, respectively (AUC 0.925, PPV; 96.3\%, NPV; 85.9\%) (Figure 3).

High levels of CA19-9 increases the risk of gallstone as AP reason by 160-fold (OR: 160, CI 95\%: 47-544).

\section{DISCUSSION}

AP is an important clinical event with an increased frequency due to increased life expectancy, obesity, and alcohol use. The most common causes of pancreatitis in the 829 patients who were evaluated in our study were gallstone (58\%), hyperlipidemia ( $8 \%)$, alcohol or drug use (8\%). In addition, gallstone-induced AP was significantly higher in females, and metabolic/ toxic AP was statistically higher in males $(p=0.001)$. In spite of developing laboratory and imaging methods, idiopathic patients continue to play an important role in the etiology (10-30\%)' We could not detect any reason that could cause AP in $17 \%$ of the cases. Laboratory tests alone are not sufficient to clarify the etiology in AP patients at admission. Imaging methods such as ultrasonography, CT, MRI, and even EUS are often needed. Especially in AP due to choledocholithiasis, alkaline phosphatase (ALP), bilirubin, gamma-glutamyltransferase (GGT) levels are important markers for pathologies in bile ducts, but it should be kept in mind that false positive and negative results can also be observed.

CA 19-9 is a glycolipid synthesized by the pancreas and ductal epithelial cells, as well as in the stomach, colon, endometrium and salivary gland epithelium cells. The primary role of CA 19-9 level is to evaluate the efficacy of palliative chemotherapy 
FIGURE 2. BOX-PLOT REPRESENTATION OF CARBOHYDRATE ANTIGEN (CA) 19-9 LEVELS IN GALLSTONE AND METABOLIC/TOXIC GROUPS

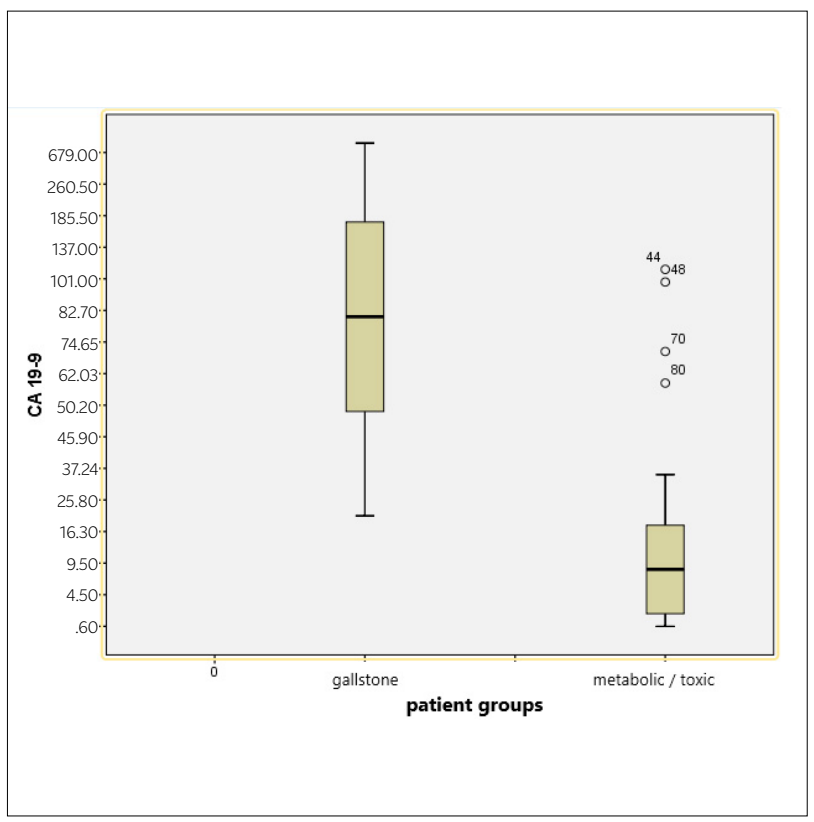

in hepatobiliary and pancreatic cancers and to follow up after curative surgery. The sensitivity of CA 19-9 in hepatobiliary malignancies was found to be above $90 \%{ }^{4}$. However, in addition to elevations in various benign events (Mirizzi syndrome, cholecystitis, choledocholithiasis, autoimmune pancreatitis, benign biliary stricture, among others) in the hepatobiliary system, it has been reported in extra-biliary events such as interstitial lung disease, tuberculosis, pneumonia, rheumatoid arthritis, and renal system malignancies ${ }^{12-19}$. CA 19-9 values above normal limits alone cannot distinguish malignant or benign causes. In a study from Morris-Stiff et al.2 , CA 19-9 levels were detected above normal values in $95.9 \%$ of patients with pancreatic adenocarcinoma, $89.5 \%$ of patients with cholangiocarcinoma, $44.4 \%$ of patients with gallstone, and $27 \%$ of patients with chronic pancreatitis. In the study, the sensitivity, specificity, PPV, and NPV values in the differentiation of malignant from benign diseases were calculated as $84.9 \%$, $69.7 \%, 67.7 \%$, and $86.1 \%$, respectively. According to the ROC curve analysis, the optimal CA 19-9 value for distinguishing malignant and benign events was $70.5 \mathrm{U} / \mathrm{ml}$. Similarly, in a study from Marrelli et al. ${ }^{20}$ that evaluated 128 patients with obstructive jaundice (87 pancreatic-biliary malignancy and 41 benign events), the CA 19-9 level was found to be high in $61 \%$ of benign events and $86 \%$ of malignant events. Kim et al. ${ }^{21}$ found CA $19-9$ levels above $37 \mathrm{U} / \mathrm{ml}$ in $90 \%$ of malignant and $59 \%$ of benign events. The mean CA
FIGURE 3. ROC CURVE FOR CARBOHYDRATE ANTIGEN 19-9 SENSITIVITY AND SPECIFICITY (CUT-OFF VALUE 37 $\mathrm{U} / \mathrm{ML})$.

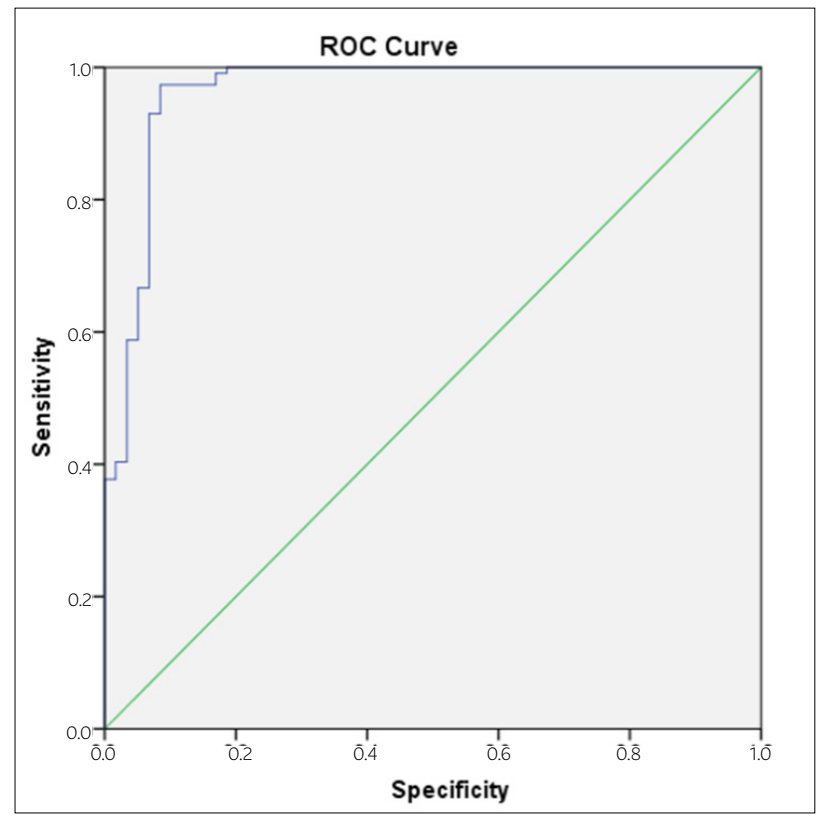

19-9 level in malignant events was $442.4 \mathrm{U} / \mathrm{ml}$, and $67.4 \mathrm{U} / \mathrm{ml}$ in benign events. In another similar study, CA 19-9 levels in benign cases were found to be 102 $\mathrm{U} / \mathrm{ml}$, and $910 \mathrm{U} / \mathrm{ml}$ in pancreaticobiliary tumors ${ }^{22}$. Ong et al. ${ }^{8}$ also showed that benign hepatobiliary diseases are associated with an increase in CA 19-9 and bilirubin levels. In a study in which Dogan et al. ${ }^{23}$ evaluated CA 19-9 levels in patients with gallstone, high CA 19-9 was detected in 32 of the 70 patients (46\%). CA 19-9 levels were not correlated with the number and diameter of the stones but were shown to be higher in patients with cholangitis.

In the literature, there are not many studies about CA 19-9 levels in patients with AP. Teng et al. ${ }^{5}$ evaluated CA19-9 levels in 693 of 1609 patients with AP,, and CA 19-9 levels were found above $37 \mathrm{U} / \mathrm{ml}$ in 186 (26.8\%) patients. CA 19-9 levels were not correlated with AP severity but with serum alkaline phosphatase, alanine aminotransferase, aspartate transaminase, and creatinine levels. In this study, the CA 19-9 level was found to be high in $53.8 \%$ of patients with gallstone-induced AP, in $11.3 \%$ of patients with alcohol-induced AP, and in $7.5 \%$ of patients with hypertriglyceridemia induced AP. However, there is no data about when the evaluation of CA 19-9 was made. In addition, in another prospective study of CA 19-9 and CEA levels in 61 patients with AP, the CA 19-9 level was found to be high in $36 \%$ of the patients ${ }^{24}$. There were no significant differences in the rates of CA 19-9 in patients with AP (34 patients), including 
pancreatitis due to gallstone and other reasons. The number of patients with metabolic/toxic causes of AP was low (12 patients), and the inclusion of idiopathic patients in the study was seen as a disadvantage.

The CA 19-9 levels of the 173 patients included in our study were evaluated within 24 hours after diagnosis, and CA 19-9 levels were detected high (> 37 U/ml) in 109 (63\%) of the cases. In our study, CA 19-9 levels were above $37 \mathrm{U} / \mathrm{ml}$ in $92 \%$ of patients with AP due to gallstone, and the mean CA 19-9 level was found to be 206.1 U/ml. CA 19-9 levels were in the normal range in $93.2 \%$ of the patients who developed pancreatitis due to metabolic/toxic causes, and the mean CA 19-9 level was found to be $14.6 \mathrm{U} / \mathrm{ml}$ in these patients. There were also statistically significant differences between the groups in terms of levels of amylase, lipase, AST, ALT, and bilirubin in addition to CA 19-9 levels. These data show that CA 19-9 levels are high in clinical events in the bile ducts not only in patients with biliary tract malignancies but also in patients with stasis like gallstones $^{25}$. It shows that CA 19-9 levels, especially in the early period of AP, are an important predictor for the etiology of pancreatitis.

Our study is retrospective, and prospective studies are needed for CA 19-9 levels in patients with pancreatitis after bile duct drainage and after pancreatitis regression, as well as in all pancreatitis groups. In addition, prospective studies are needed to determine whether CA 19-9 can contribute to diagnostic in idiopathic cases.

\section{CONCLUSION}

CA 19-9 levels at an early stage in patients diagnosed with AP may provide an additional contribution to standard laboratory tests. In pancreatitis patients with high CA 19-9 levels, in particular, it is possible to say that there is a clinical event which causes stasis in the biliary tract. We believe that an additional imaging technique for the biliary tract, such as EUS, will be useful before the diagnosis of idiopathic pancreatitis in patients with normal USG, CT, and MRCP findings and high CA 19-9 levels. We think it is appropriate to consider the metabolic/toxic causes of pancreatitis in patients with mild cholestatic enzyme elevation if the CA 19-9 level is normal.

\section{Conflict of interest}

None.

\section{Authors' Contribution}

Concept: OBB. Design: OBB. Supervision: ZBP. Materials: OBB, ZBP. Data collection and/or processing: ZBP. Analysis and/or interpretation: OBB, ZBP. Literature search: OBB. Writing: OBB. Critical reviews: OBB, ZBP.

\section{RESUMO}

OBJETIVO: A pancreatite aguda (PA) é um evento clínico importante e cada vez mais frequente devido ao aumento da expectativa de vida, obesidade e do consumo de álcool. Existem alguns dados na literatura sobre a elevação dos níveis do antígeno carboidrato (CA) 19-9 em eventos pancreato-biliares benignos e malignos, mas eles são limitados em relação à PA. O objetivo deste estudo foi avaliar o nivel de CA 19-9 em pacientes com PA e determinar sua relação com a causa da doença.

PACIENTES E MÉTODOS: Entre 2010 e 2018, 173 pacientes submetidos a uma avaliação dos níveis de CA 19-9, bem como testes laboratoriais padrão, foram incluídos no estudo. Os níveis de CA 19-9 e os achados laboratoriais foram comparados em pacientes com pancreatite devido a cálculos biliares (grupo 1) e razões metabólicas/tóxicas, como hiperlipidemia, álcool, ou uso de drogas (grupo 2).

RESULTADOS: Um total de 114 (66\%) pacientes foi incluído no grupo 1 e 59 (34\%) no grupo 2. A maioria dos pacientes com alto nível de CA 19-9 estavam no grupo 1 (92,1\% versus 6,8\%). O CA 19-9, bem como os níveis de amilase, lipase, AST, ALT e bilirrubina foram estatisticamente mais altos em pacientes com PA devido a cálculos biliares em comparação àqueles com PA devido a alterações metabólicas/tóxicas.

CONCLUSÃO: Pacientes com PA devido a cálculos biliares apresentaram um alto nível de CA 19-9 no momento da internação. O nível de CA 19-9 na fase inicial pode contribuir para testes laboratoriais padrão na etiologia da doença em pacientes com diagnóstico de PA.

PALAVRAS-CHAVE: Pancreatite necrosante aguda. Pancreatite. Cálculos biliares. Antígeno CA-19-9.

\section{REFERENCES}

1. Roberts SE, Morrison-Rees S, John A, Williams JG, Brown TH, Samuel DG The incidence and aetiology of acute pancreatitis across Europe. Pancreatology. 2017;17(2):155-65.

2. Morris-Stiff G, Teli M, Jardine N, Puntis M. CA19-9 antigen levels can distinguish between benign and malignant pancreaticobiliary disease. Hepatobiliary Pancreat Dis Int. 2009;8(6):620-6.

3. Pandiaraja J, Viswanathan S, Antomy TB, Thirumuruganand S, Kumaresan DS. The role of CA19-9 in predicting tumour resectability in carcinoma head of pancreas. J Clin Diagn Res. 2016;10(3):PC06-9. 
4. Goonetilleke KS, Siriwardena AK. Systematic review of carbohydrate antigen (CA 19-9) as a biochemical marker in the diagnosis of pancreatic cancer. Eur J Surg Oncol. 2007;33(3):266-70.

5. Teng D, Wu K, Sun Y, Zhang M, Wang D, Wu J, et al. Significant increased CA199 levels in acute pancreatitis patients predicts the presence of pancreatic cancer. Oncotarget. 2018;9(16):12745-53.

6. Yamamoto Y, Sugiura T, Todaka A, Okamura Y, Ito T, Ashida R, et al. Surgical indication for advanced intrahepatic cholangiocarcinoma according to the optimal preoperative carbohydrate antigen 19-9 cutoff value. World I Surg. 2018:42(10):3331-40.

7. Zhuge $X$, Guo $C$, Chen $Y$, Feng L, Jia R, Zhao Y, et al. The levels of tumor markers in pancreatic neuroendocrine carcinoma and their values in differentiation between pancreatic neuroendocrine carcinoma and pancreatic ductal adenocarcinoma. Pancreas. 2018;47(10):1290-5

8. Ong SL, Sachdeva A, Garcea G, Gravante G, Metcalfe MS, Lloyd DM, et al. Elevation of carbohydrate antigen 19.9 in benign hepatobiliary conditions and its correlation with serum bilirubin concentration. Dig Dis Sci. 2008;53(12):3213-7.

9. Sheen-Chen SM, Sun CK, Liu YW, Eng HL, Ko SF, Kuo CH. Extremely elevated CA19-9 in acute cholangitis. Dig Dis Sci. 2007;52(11):3140-2.

10. Bertino G, Ardiri AM, Calvagno GS, Malaguarnera G, Interlandi D, Vacante $M$, et al. Carbohydrate 19.9 antigen serum levels in liver disease. Biomed Res Int. 2013:2013:531640.

11. Katsanos KH, Kitsanou M, Christodoulou DK, Tsianos EV. High CA 19-9 levels in benign biliary tract diseases. Report of four cases and review of the literature. Eur | Intern Med. 2002;13(2):132-5.

12. Lowe D, Lee J, Schade R, Chaudhary A. Patient with markedly elevated CA 19-9 not associated with malignancy. South Med J. 2006;99(3):306-8

13. Shin JY, Yoo SJ, Park BM, Jung SS, Kim JO, Lee JE. Extremely increased serum carbohydrate antigen 19-9 levels caused by new or resistant infections to previous antibiotics in chronic lung diseases. Tuberc Respir Dis (Seoul). 2013;75(3):125-7.

14. Kodama T, Satoh H, Ishikawa H, Ohtsuka M. Serum levels of CA19-9 in patients with nonmalignant respiratory diseases. I Clin Lab Anal. 2007;21(2):103-6

15. Onishi T, Franco OE, Shibahara T, Arima K, Sugimura Y. Papillary adenocarcinoma of the renal pelvis and ureter producing carcinoembryonic antigen, carbohydrate antigen 19-9 and carbohydrate antigen 125. Int | Urol. 2005;12(2):214-6.

16. Robertson AG, Davidson BR. Mirizzi syndrome complicating an anomalous biliary tract: a novel cause of a hugely elevated CA19-9. Eur I Gastroenterol Hepatol. 2007:19(2):167-9.

17. Szekanecz E, Sándor Z, Antal-Szalmás P, Soós L, Lakos G, Besenyei T, et al. Increased production of the soluble tumor-associated antigens CA19-9, CA125, and CA15-3 in rheumatoid arthritis: potential adhesion molecules in synovial inflammation? Ann N Y Acad Sci. 2007;1108:359-71.

18. Toomey DP, Swan N, Torreggiani W, Conlon KC. Autoimmune pancreatitis: medical and surgical management. JOP. 2007;8(3):335-43.

19. Uygur-Bayramicli O, Dabak R, Orbay E, Dolapcioglu C, Sargin M, Kilicoglu G, et al. Type 2 diabetes mellitus and CA 19-9 levels. World | Gastroenterol. 2007;13(40):5357-9

20. Marrelli D, Caruso S, Pedrazzani C, Neri A, Fernandes E, Marini M, et al. CA19-9 serum levels in obstructive jaundice: clinical value in benign and malignant conditions. Am J Surg. 2009;198(3):333-9.

21. Kim MS, Jeon TI, Park JY, Choi J, Shin WC, Park SE, et al. Clinical interpretation of elevated CA 19-9 levels in obstructive jaundice following benign and malignant pancreatobiliary disease. Korean J Gastroenterol. 2017;70(2):96-102.

22. Mann DV, Edwards R, Ho S, Lau WY, Glazer G. Elevated tumour marker CA19-9: clinical interpretation and influence of obstructive jaundice. Eur | Surg Oncol. 2000;26(5):474-9.

23. Doğan ÜB, Gümürdülü $Y$, Gölge N, Kara B. Relationship of CA 19-9 with choledocholithiasis and cholangitis. Turk | Gastroenterol. 2011;22(2):171-7.

24. Cüre E, Baştürk $A$, Şahin $M$, Cüre MC, Coşkun HŞ, İşler M. The evaluation of tumor markers in acute pancreatitis. Turk J Cancer. 2007;37(1):11-5.

25. Marrelli D, Pinto E, De Stefano A, Farnetani M, Garosi L, Roviello F. Clinical utility of CEA, CA 19-9, and CA 72-4 in the follow-up of patients with resectable gastric cancer. Am J Surg. 2001;181(1):16-9. 